\title{
Feminine or feminist? Women's media leadership
}

\section{Anne O'Brien}

To cite this article: Anne O'Brien (2017) Feminine or feminist? Women's media leadership, Feminist Media Studies, 17:5, 836-850, DOI: 10.1080/14680777.2017.1300593

To link to this article: https://doi.org/10.1080/14680777.2017.1300593

\section{Published online: 14 Mar 2017.}

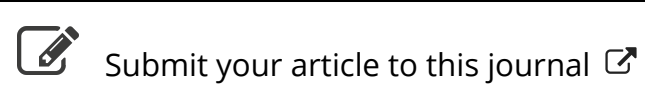

$$
\text { Џ Article views: } 887
$$

\section{Q View related articles $₫$}

View Crossmark data $־$

Citing articles: 1 View citing articles ๘ 


\title{
Feminine or feminist? Women's media leadership
}

\author{
Anne O'Brien
}

Department of Media Studies, Maynooth University, Maynooth, Ireland

\begin{abstract}
This paper presents a small-scale qualitative case study of five women's experiences of leadership roles in Irish media industries. Relational Leadership Theory is used to examine whether there is a gendered dimension to women's leadership and to explore why women's participation in leadership has not resulted in significant feminist gains or changes to media organisations. The article finds that: the women saw their leadership as relational and simultaneously as socially constructed in a gendered manner. Moreover, the women led organisational change towards greater gender equality in the norms of media work. However, while the women's leadership was relational and feminine, it was not necessarily feminist; it did not aim to generate systemic changes within the gendering of the media as an institution. The changes that the women wrought incorporated women into a system of production that remained nonetheless masculinist.
\end{abstract}

\section{ARTICLE HISTORY}

Received 4 April 2016 Revised 10 October 2016 Accepted 3 November 2016

\section{KEYWORDS}

Relational Leadership; decision makers; media organisations; Ireland

\section{Introduction}

That women are a minority in media leadership has been clearly established at global, European, and national levels. Studies by professional bodies such as the International (and European) Federation of Journalists, NGOs such as the European Women's Lobby, the various Working Groups of the European Commission, and the Council of Europe (Karen Ross 2014, 37) have established that there are few women in decision-making roles in media industries. Globally, Carolyn M. Byerly found that women held only 27 percent of top management jobs (2011) and currently women in Europe occupy around one-third of all leadership positions in public service broadcasting organisations and around one-quarter of positions in the private sector (Ross 2014). Women continue to be under-represented in the decision-making structures of major media organisation "both at operational levels as senior managers and at strategic levels, as CEOs and board members" (Ross 2014, 39). Nationally, in Ireland, only 12 percent of women occupy senior decision-making roles (European Institute for Gender Equality 2013).

Looking at the quantitative issue of women's presence in leadership is important in terms of mapping the extent of their exclusion from such roles. However there is also a need to map the qualitative nature of women's minority experience of leadership, to ask how women 
see, obtain, and experience those roles. While a number of studies examine women workers' experiences of gendered newsrooms, such as Margareta Melin-Higgins (2004) and Elizabeth van Zoonen (1989), nonetheless a lacunae exists in knowledge about female media leaders more specifically. This has only recently begun to be addressed in key works that document the "glass architecture" that constrains women in achieving senior positions (Gay Bryant 1985; Michelle K. Ryan and S. Alexander Haslam 2007; Linda Steiner 2015) and in work such as Alice H. Eagly and Linda L. Carli's on the leadership "labyrinth" (2007) as well as in Valerie Stead and Carole Elliott's (2009) work on how gender shapes images of and expectations about leaders. Carolyn Byerly and Karen Ross do document "the tiny proportion of women working in senior positions in the media" and argue that "women experience the glass ceiling effect when they make steady progress as entrants into the sector but then do not go on to achieve senior positions" $(2004,77)$ but they do not discuss or theorise women's actual experiences in leadership roles. Questions thus remain as to how women see their own subjective experience of leadership, how they define it and how they experience it as gendered. It is to those subjective views that this article is addressed.

This research is based on data collected through semi-structured interviews with five women who held leadership roles in Irish media: Helen Shaw, Managing Director RTÉ Public Service Radio 1997-2002; Geraldine Kennedy, Editor of The Irish Times from 2002 to 2011; Clare Duignan, Director of Programmes Television (RTÉ) Public Service Television and Managing Director RTÉ Radio 2003-2013; Claire Grady, Editor of the Irish Independent 20132014; and Noirín Hegarty, Editor of the Sunday Tribune 2005-2011. Leadership is defined as persons holding or having held a senior managerial position in production, operating at top-level decision making with control over editorial, policy, and budgets. Typically they were operational heads of stations or in chief editor roles. The women were asked about how they got into media work, how they sustained careers and succeeded against the likely odds, and how they experienced their leadership roles in terms that they believed to be relevant to gender.

\section{Leadership literature}

Relational Leadership Theory (RLT), which sees leadership as a socially constructed change process (Mary Uhl-Bien 2011,66), is a useful analytical lens for analysing the Irish case because it engages with the key characteristics of leadership as articulated by the interviewees. The relational perspective describes leadership as socially constructed in the process of relating (Diane M. Hosking, H. Peter Dachler, and Kenneth J. Gergen 1995) and as inherently subjective and interdependent (Uhl-Bien 2011,67). Leadership in that sense is not restricted to hierarchical positions or management roles but rather it is seen as a set of influential acts of organising that come to structure interactions and relationships within organisations. As Uhl-Bien notes "leadership relationships are identified by interactive dynamics that contribute to the emergence or direction of social order and action" $(2011,96)$. Relational leadership thus examines the whole "process by which social systems change" as well as describing the "socially constructed roles and relationships developed that might be labelled leadership" (Kenneth L. Murrell 1997, 39).

RLT does not overtly address gender as such, but as Uhl-Bien crucially highlights, its "themes are not gender neutral" $(2011,66)$. Uhl-Bien observes that relational leadership's "associated focus on interdependencies, collective achievement, collaboration and 
mutuality" belong to a "feminine discourse" $(2011,67)$. Uhl-Bien applies Nanette Fondas' (1997) delineation of feminine qualities-broadly described as interpersonal sensitivity, responsiveness, orientation toward collectivity, and actualising values - to RLT and argues that it contains feminine elements (2011). Joyce K. Fletcher argues that concepts of relationality are not gender, power, or sex neutral but instead are rooted in a set of social interactions in which "doing gender," "doing power," and "doing leadership" are linked in complex ways $(2004,648)$. Leadership traits "such as empathy, community, vulnerability, and skills of inquiry and collaboration - are socially ascribed to women in our culture" and generally understood as characteristic of feminine leadership (Fletcher 2004, 650). Women come to do feminine leadership by doing gender, by "defining themselves in relation to gendered stereotypes" (Fletcher 2004, 650). The shift towards relational leadership

from individual to collective, from control to learning, from "self" to "self in relation," and from power over to power with -is a paradigm shift ... even more profound and difficult to achieve than the leadership literature would have us believe because it is a shift that is related in complex ways to systemic gender and power dynamics in the workplace. (Fletcher 2004, 650)

This intricate connection between relationality and gender is useful to understanding the interviewees' views on their leadership, which they described in ways that can be understood as both relational and gendered.

While the interviewees' leadership can be understood in terms of RLT as will be described below, certain dimensions of their careers can also be re-conceptualised as acts of relational leadership in accordance with the RLT paradigm. If relational leadership occurs "when the social influence that is generated contributes to the emergence of social order (i.e. emergent coordination) and new approaches, attitudes, goals etc. (i.e. change)" (Uhl-Bien 2011, 95), then the women interviewed all influenced social change and a new social order in terms of attitudes towards gender and inclusion, through their willingness to be and to remain gender-anomalous workers in a male-dominated setting. Women entering male-dominated media work is an act of relational feminine leadership. These actions are not normally understood as leadership actions but RLT facilitates a re-conceptualisation of these actions as acts of leadership. However, a feminine mode of leadership that is relational does not necessarily constitute a feminist mode of leadership, which would require the de-masculinisation of leadership. Merely welcoming feminine traits or the "female advantage" (Alice H. Eagly 2007) of relational capacity into a paradigm of leadership that remains fundamentally masculinist, does not constitute a radically altered or feminist mode of leadership; it does not demand structural transformation. Feminist leadership is motivated by fairness, justice, and equality at micro and macro levels and is characterised by a transformative agenda that exposes and challenges patriarchy (Peggy Antrobus 2000; Tracy Barton 2006). This latter distinction between feminine and feminist leaderships may begin to explain why, despite the presence of women in leadership roles, little change has been documented for women workers in media industries (Byerly and Ross 2004, 77).

\section{Methodology}

Ireland is an important site for a case study on women's leadership because its record on gender equality in media work is relatively poor compared with other European states. The Irish communications sector employs approximately seventy-thousand people but women comprise only 30 percent of that workforce, compared to a European average of 44 percent 
female employment in programming and broadcasting (EIGE 2013, 16). Irish women comprise only 12 percent of decision makers in media organisations relative to a European average of 32 percent (EIGE 2013,31). The findings from Ireland are particularly relevant to other EU states such as Italy, Malta, and Greece, where women are similarly under-represented in decision-making roles. Ireland is also useful as a case study because the industry shares the typical structures of the European media industry, but on a smaller scale. Irish broadcasting has a mix of public service, commercial, community, and independent actors across radio and television. Over 150 small to medium-sized independent screen production companies are active. The print industry is composed of three national daily broadsheets, six tabloids, two Sunday broadsheets, and four Sunday tabloids.

Interviews were conducted with women who held formal operational level leadership roles in public service and commercial radio and television stations and in national daily or weekly newspapers for at least one year and for a maximum of ten years. Due to the low levels of participation by women in leadership in Irish media (12 percent) the possible sample size is very small. Requests for interviews were made with all women who fit the criteria but three further possible interviews were declined. Recorded interviews were conducted directly with four women and additional data were derived from a fifth podcast recording (Hegarty 2016). The four key informants were the main source of data and the podcast was used only to confirm findings. Data were transcribed and coded thematically then the findings were generated with reference to the RLT approach to understanding gender and leadership. Extrapolating globally on the basis of a small, nationally specific sample is not possible, and so the research makes no claims at this level, but instead offers a subjective, qualitative insight into women's own accounts of gender and relational leadership experiences as they articulate them.

Gender identity is defined in the spirit of Judith Butler's ideas of performativity as a socially constructed role that prescribes appropriate norms and expectations for behaviour (1993, xii). The question of intersectionality of class and race with gender in leadership, while an important one, is not claimed as the main focus of the analysis. The article does not make claims for gender essentialism; identities across the spectrum can have "feminine"leadership capacities because these are socially constructed, practice based, and thus open to revision and change. In addition the analysis examines only how the women define themselves in terms of their leader relationships to others; it does not claim to examine the totality of the leadership relationships in any objective or collective sense by gathering data on men or on followers who worked with the women. That remains an area for further, potentially rich, study.

\section{Findings}

The women's leadership can be understood as relational in a number of ways. Firstly, they saw their leadership as collaborative but simultaneously as socially constructed in a gendered manner, that is, it was identified as a "feminine" form of leadership derived from the fact of the leaders being female. Secondly, by entering into and preserving in a masculinist industry they impacted on the social order of how gender and leadership interact and influenced organisational change towards greater gender equality in media industries in ways that need to be conceptualised as leadership actions. Thirdly, although the women's acts of leadership led to changes for women within media industries, it did not however lead to a 
fundamental de-masculinisation of media work, which still remains a predominantly masculine work culture in Ireland (Anne O'Brien 2014). The explanation for this is that while relational and adaptive leadership theory describes the feminine traits (Fondas 1997) of leadership, which opens up ways of theorising the unique contribution that women (and men) can make to organisations, relational leadership does not demand systemic changes in the way that a more explicitly feminist leadership might. The women lead changes that shifted the gender norms of industry to include women but they did not go so far as to demand systemic level changes that would have seen a more radical overhaul of gender imbalances within media industries. While their leadership was feminine it wasn't feminist.

\section{Leadership as relational and gendered}

The women defined their leadership as relational in similar terms to those outlined by Fletcher (2004). They placed an emphasis on collaboration and on the collective; they prioritised engagement over control; and they did not conceptualise their leadership in egotistical terms of the "self" but rather in terms of the "self in relation" (Fletcher 2004, 650). The women articulated these characteristics of their leadership in three key ways: firstly, they were explicitly conscious of their gendered work context and the relational nature of their leadership; secondly, they were highly relational in wishing to retain an emotional connection to their work and to maintain a value of care within their leadership; and thirdly, the women lead differently because their leadership context was not exclusively focused on the "self" but on "self in relation," both to the work context but also to the relevance of relationships outside of work. They noted how access to family supports was very different for the women interviewed than for their male colleagues, which they believed impacted back on their work. This latter characteristic raises a challenge for theories of leadership, which have not thus far looked outside of the formal work context to explore how other non-work relationships might impact upon capacities for relational leadership in work settings.

On the question of gender and leading differently, Hegarty found the normative male management models in newspapers incredibly aggressive. It was normal for editors to publicly reprimand workers. She notes

If I'm really candid and honest about it I learned how not to manage from the male editors who managed me. I saw how they affected people (negatively) ... I remember thinking if I ever got to a position like that I wanted people to come out of my office being more inspired, more willing to work harder and do more, rather coming out feeling useless and disillusioned because you've been bawled at.

Hegarty took the opposite approach and moved away from a "control over" to a "learning with" model: "If you can adopt a collaborative approach you don't have all the responsibility personally but you can also inspire people to do their best." Duignan also emphasised the idea of shared responsibility, consultation, and collaboration and the creation of group cohesion within her management team: "I would have a very collegiate leadership style it would matter to me to get buy in from my management team in particular. I would want them to support decision ... l'd do more staff meetings than other heads." She elaborates on the importance of consultation and engagement with her team and the benefit that followers derived from it: "I would be the kind of manager who would meet and talk to people a lot and I would have done that tapping on the shoulder telling people to go for things." Duignan 
notes also the gendered dimension of her relational approach "but a lot of it was encouraging women, offering training, giving feedback to women."

The female decision makers generally noted that their values or ethics as individuals was something that they wished to carry into and hold in their leadership practice and they saw this relational dimension of leadership in explicitly gendered terms. As Shaw puts this, "I think its complex ... but yes I do think I lead differently ... but a lot it came from having a very clear ethical base." Shaw was unequivocal about retaining her own integrity on decisions:

I wouldn't compromise on doing favours, on politics, on playing the game and sometimes that put you at odds with both your friends and your colleagues. But for me the concept of doing the work, of doing good work, was more important than being liked ....

Grady concurs on the centrality of values to her leadership but with a similar qualification to Shaw on the specificity of gender as a causative force in the context of leadership:

I do think women lead differently to men ... I would find it much more difficult to separate the values that I have and the sort of person that I am from work needing to be done in a particular way.

Both Duignan and Grady spoke in particular about the difficulty of managing relationships in a period of austerity and the impact of making employees redundant: "It was a very difficult time for the organisations with redundancies coming up people being redeployed and a lot of uncertainty and I found that difficult."

Grady observes a differentiation in gender terms around a leader's capacity to distance themselves from the personal impact of those hard decisions. As Grady puts it:

I don't know if men in similar roles to me would have had the same level of upset about it ... men seem to be able to separate out whatever their values are for themselves from what needs to be done. They take a greater pride in saying "well that's what needs to be done."

Grady notes that this masculinist position was institutionalised in the culture of the news organisation

I was told by a senior person time and time again "you're not here to make friends" ... but it chills me a little bit when people say not to court popularity but that wasn't what I was trying to do, I was just trying to be decent to people.

For women in one newspaper there was a particularly harsh climate that created an aggressive context within which they tried to lead in a way that did not compromise their relational leadership values around collaboration and consultation. This created a double burden for them in their decision-making roles; on the one hand they had to function within an aggressive masculinist management context but on the other hand they had to try to lead effectively while retaining some emotional involvement and collaboration with colleagues. This dilemma speaks to the invisibility of relational skills in media industries and the tendencies to undervalue emotional labour as an important part of production work and management (Anne O'Brien 2015).

The women said that they lead differently, relationally, by holding a value of care within their leadership but the women also lead differently because the context for the "self" in the leadership role and the "self in relation" to others was different for the women than for their male peers. The women's experience of family and the supports it could offer to the leading "self" at work was very different for the women interviewed than for their male colleagues. Once she achieved the post of editor Grady was conscious of being an outlier in the 
management structure because of her domestic context-she was the only woman who did not have a fulltime homemaker spouse. The normativity of traditional family support structures and the social benefit derived for her male colleagues was striking for Grady:

A lot of senior men (on the back desk) were married to women who did not work outside the home and it offered them a level of support that was not available to women, ones who had kids and were trying to manage it all. [...] For the two women (on the back desk) they were doing a full day of intensive work and then going home at 3 to pick up the kids and do another 8 hours.

As well as receiving gendered support in terms of the social reproduction of the worker there was a direct benefit to the men in terms of their relative freedom from care work and a presumed availability for formal work: "Unsocial hours were not an issue for those guys." By contrast their female equivalents felt the pressure of the second shift of care work that occurred outside of their formal employment. In Fletcher's terms, the "self in relation" for the women leaders was doubly burdened by the context outside work where they simultaneously did not receive support from a fulltime homemaker spouse but also they had to provide the care labour in their own domestic context.

Any acknowledgement of this double burden on women leaders was rare in commercial media. Hegarty was conscious that there weren't many women who were mothers in jobs like hers: "So there wasn't very much understanding or support for it." Duignan also combined management with motherhood and proposed that this should be a priority consideration for organisations in retaining female decision makers:

If organisations want to retain women and see them progress, you don't want them leaving all the time. As you recruit women you have to offer support and continue to offer support, find the role models in the organisations and make them public, acknowledge them and create the mentoring schemes or championing schemes make it acceptable-I had three children while I had that career-for people to leave for a period of time ....

Hegarty commented insightfully on the need for social change around expectations of women and work-life balance:

... I don't know that you have all that time to do the networking, to go to the pub, the evening stuff and even if you could do it would you choose to do it? Is it the stuff that's comfortable for you? It's not really for most women ....

Hegarty is clear that her self-imposed exclusion from that culture due to her status as a woman and a mother did impact on her "self in relation" to colleagues and on her career progression and the sustainability of her career in the long term. By not participating in the networks Hegarty's relationship with colleagues was impacted:

I think that's where I went wrong because I don't think I was (seen as) trustworthy. I think they saw me as an alien ... and I don't think that was fair personally but I wasn't there (in the pub) to counter it.

Relational leadership theory needs to further consider how the "self in relation," outside of the formal work space and context, is impacted in heavily gendered ways, whereby women's capacity to lead, cover the second care shift, and in addition work on relationships outside of work are all very affected by gendered structures of work.

This pattern of traditional domestic arrangements that facilitated the availability of men, combined with a work culture that demanded participation socially in out of hours events, ultimately invisibly advantaged men and simultaneously disadvantaged women. The key point here is that there was no renegotiation of work practices or culture to acknowledge women's potentially different needs or desires. As Grady puts it succinctly: 
If you can't structure a job so that people can give it their all in 8 hours then there's something wrong with the job ... you should be able to harness the capabilities of people so that they can segment their lives....

On the question of how this situation should be rectified Grady is clear that it's not only a quantitative shift in women's participation that is required but also a more radical cultural shift in the organisation of work that overtly acknowledged that it is gendered in favour of masculine normativity:"I think you need to not have that macho attitude that you're married to the job. A lot of women wouldn't be in a position to do that." Hegarty notes in addition that the only way of circumventing a masculine model of complete availability to work with a corresponding pattern of the exclusion of women from decision making was to acknowledge "there needs to be that critical mass in a work environment where women are not alone. And where it's not seen as odd that you might have to go pick up the kids from school."

In summary, the women described their leadership as something that occurred through relationships, in terms of an openness to bottom-up influence (David Bradford and Allan Cohen 1998) to "connective" leadership (Jean Lipman Blumen 1996) and to an emphasis on collaborative, fluid, egalitarian, more mutual and less hierarchical leadership "as well as a more welcoming, less competitive stance towards others" (Fletcher 2004).

While the women articulated their leadership in gendered terms and clearly as relational, there are other ways in which their careers and actions can be conceptualised as relational leadership. Throughout the 1970s and 1980s the women's participation in media industries was a challenge to the masculine exclusivity of the sector. Over time the women's persistence, resilience, and ultimately success in achieving decision-making roles influenced social change by making it easier for women to work in media industries. These actions should be understood as acts of relational leadership.

\section{Relational leadership as changing gender norms}

The women leaders examined here were anomalous as women in Irish media industries in three key ways. They were often the first females to enter the newsrooms and studios of Irish media industries. They were later the first women to achieve management roles in industry. And they held these positions oftentimes as the only female senior decision maker in their organisations. Their survival and success, and the way that this forced a shift in the normalcy of women in media work, corresponds with Relational Leadership Theory's definition of leadership as something that constitutes a social influence on organisations and that contributes to the emergence or direction of social order. The women leaders changed gender norms by getting into, staying in, and getting on in male-dominated media industries.

Geraldine Kennedy, who would later become the first female editor of The Irish Times, was one of the first women to gain an entry level position in its exclusively male newsroom in the early 1970s. She adapted to this environment in relational terms by ensuring her presence was acceptable to the male workforce by adopting the normative, albeit masculine expectations for the role:

I was anxious at the time that if I was doing news that l'd be doing it on the same terms as the men, in other words the long hours and at night, that sort of thing. I fought for that so that the men wouldn't resent me. 
Despite Kennedy's willingness to operate on the same terms as her male colleagues she found that her access to equal treatment was blocked by gender role stereotypes of what was deemed appropriate for women journalists:

I wanted to do night-town which meant you were on duty from $10 \mathrm{pm}$ until 3 or 4 in the morning and it meant that you made all the calls, the decisions ... but under some industrial relations legislation they wouldn't let me do it, women couldn't work past 11 pm.

Undeterred, Kennedy circumvented this gendered exclusion by being opportunistic "after 3 or 4 months the full time night editor didn't turn up ... so I did it ... that's how I got doing things." Kennedy's opportunism can be understood as an act of relational leadership. As a women she continually but gradually broke the taboos of an exclusively male space and forced the organisation to accept a female journalist. While this is regularly articulated in the literature as "breaking the glass ceiling," here it can be clearly understood also as an act of leadership in which, through her relationships with colleagues, she created social change and a new social order in terms of attitudes towards gender and inclusion in the newsroom.

Similarly the women's carer progression and inclusion in leadership roles required them to enact a form of relational leadership, which saw them structuring interactions and relationships within organisations that changed the gendered order. The way that the interviewees persevered in their careers and forced social systems to change and thereby socially reconstructed access to leadership roles is most accurately described as relational leadership. The women enacted relational leadership by circumventing negative relationships and attempts to block their progress and by being exceptionally good at their jobs in order to achieve roles obtained by more mediocre male colleagues. While these women were "allowed" to be the first junior reporters into print newsrooms and progressed to series producer roles in radio where the novelty factor of their participation was well received in the 1970s and 1980s, in a relatively newer, arguably more prestigious medium such as television, from where a majority of senior managers would eventually be recruited, where there was more at stake in terms of promotion, more to be gained or lost for career progression, women were less welcomed into the "boys club."

Transferring to television production in 1980 Duignan experienced a clear discrimination against being female: "On the TV training course there were much more men than women on it. There was a view that the guys got the better assignments." She connects this female disadvantage explicitly to the masculinised context or work culture of television at that time: "There was a view that the guys were edgier, tougher, that telly was very macho in those days." She explains the disadvantage in gender terms, noting the absolute dearth of women working in television: "There were no women camera people, no women sound operators, no women floor managers. So you went in as a women producer-director and you were in charge and that was quite challenging." Duignan had to relate to her exclusively male peers in a manner that required relational expertise but which also meant she was taken seriously in a masculinist work culture. During a live studio production she recounted that

one guy had given trouble all night, mishearing cues and being nippy so I asked him to stay back. He kept me waiting. He was 48 and I was 25 ... I was very nervous tackling him ... but I did it. I'd often be quaking inside but it wouldn't show ... you had to be adroit dealing with that.

Duignan's adroitness not only ensured her credibility as a director but also ensured that a new social norm was initiated whereby a path could be made for women to work in the no longer exclusively male arena of TV studio production. 
For Shaw her leadership saw her create a new path and a significant social change for women who were not normatively considered "management" material in radio. Gender became a distinct problem when she tried to get beyond the role of radio producer in RTÉ and into management roles. She became acutely aware at this juncture of the masculinised context in which she worked:

There were very few middle management jobs in RTÉ and there were no women in them. The line managers were all male, the middle managers were all male ... Managers were all male, that penny was beginning to drop with me, the same as at The Irish Times, management was male.

Shaw notes that as she started to apply for management posts, her progress was blocked:

If I applied feedback was you didn't have enough experience or "who do you think you are, you're in far too much of a hurry" ... I was proposing new programmes but there was a very blocking middle manager who in hindsight I think saw me as a threat and spent most of his life trying to undermine and block me and make sure I didn't get pay increments, I got badly shafted because he saw me as a threat.

A key characteristic that these women all shared under the circumstance of gendered challenges to their career progression was their remarkable resilience and capacity to adapt in the face of gendered blocking actions and disproportionate expectations. This can be understood in terms of Fletcher's observations that doing gender, doing power, and doing leadership are "linked in complex ways" $(2004,648)$. The women had a capacity to see that the external restrictions put on them doing gender and doing power were structural and they did not internalise the limitations. Where other employees may have suffered a blow to their confidence and questioned their own capacities, when faced with limitations around her participation in the role of news journalist Kennedy did not internalise the judgement, she simply waited for opportunities where she could push for parity of participation. Similarly, Shaw is clear that the problem with career progression was objective not subjective and that it was highly gendered. Rather than internalise the consequence of knock-backs and defeats, Shaw connects them explicitly with the masculinised "normalcy" of media work in terms of women's minority presence generally, a dearth of role models or mentors in management positions, and women's absence from decision-making roles in particular:

The normalcy was that there were lot and lots of women in administration and in support roles and some in production, but there were very few female radio producers .... and there were no women in decision-making roles. And the key movers and shakers were all men ....

This is where the women's capacity to "do power" despite the normative assumptions about how they should be "doing gender" meant that they could endure the knock-backs and persevere in their insistence that they be included in leadership roles. This resistance to doing gender while insisting on doing power eventually forced social systems to change and effectively reconstructed leadership roles as something women were eligible for, a practice that is most accurately described as a form of relational leadership that the women adopted before they ever achieved any formal leadership roles.

\section{First and only, women changing leadership}

In the 1990s Shaw responded to being blocked in RTÉ by moving to a more senior role as Head of News and Current Affairs in BBC Northern Ireland. She explains that doing gender, doing power, and doing leadership were all in flux in the context in which she formally achieved a leadership role. Shaw explains her success in Northern Ireland in terms of a 
changing external power context, a post-ceasefire social and political context in which difference and change were valued: "The first time I went into management I was not just the first woman, I was the youngest and I was also from the Republic ...." These differences allowed Shaw to relate differently within her leadership role, as she notes,

When I took over the BBC was very male ... (But) we were in a culture that was trying to understand change ... you were in an environment of change ... and I got the job not because of but gender was a factor-a bright young woman and she's not from here ....

For Shaw not being male and not being unionist allowed her to relate differently both within the organisation and outside in the society more generally. Using gender difference as a tool or a"novelty" advantage to do power and leadership differently were key in Shaw's case.

Duignan describes her achievement of senior roles in television at RTÉ in terms of a couple of key appointments. In 1986 she became Head of Features and then Group Head, Features and Current Affairs in 1990. Interestingly she is the only woman who situates promotion within a broader organisational context of a movement towards inclusion of women that was promoted by her employer RTÉ. It seems that Duignan's career corresponded with a fundamental shift in organisational position at RTÉ around gender and its relevance to the station:

They had a very mixed workforce and were conscious of having very few women in management ... there was a sense that women's issues weren't being addressed and if they weren't it was because there weren't women in decision-making roles and so that needed to be addressed ... and I'd credit the organisation for that and women started to come through in leadership roles and RTÉ was very active in trying to address that.

Despite RTÉ's espousal of gender balance as a desirable feature of management, nonetheless for many years Duignan was the only woman in management. At times being the only woman in management made any form of relational leadership difficult, as it impacted on the sense of collegiality and collectivity. Duignan notes that she adopted a filtering mechanism of gender "blindness," to facilitate her in getting on with the job:

For a long time when I was in senior roles in RTÉ there were almost no other women in senior roles, so you had no sense of collegiality and I realised that in a way I'm very gender blind, I spent a lot of time in senior management meetings where I was the only woman for years and years and I think I filtered it out and stopped being aware of it ....

Despite an overt policy of promoting women in management there was not initially a corresponding cultural shift within the organisation. Nonetheless Duignan herself assumed leadership roles and executed them in a relational style, as noted in the previous section. This uniqueness and the willingness to again be the "first" or "only" woman in a power role shifted the normativity of how doing gender and doing power and doing leadership could be rethought, which is in itself an act of leadership for social change.

Duignan became Head of the Independent Production Unit in 1993 and Head of Television in 2001 and she observed that it was only then that there were more women in management. She does note something of a shift in organisational culture around women leaders:

... there were a lot more women working as Head of Departments. And a female Director of Finance came in, and a Commercial Director joined and a Head of Radio and Communications and over time even all-male production grades had become more female ....

Over the course of Duignan's career she notes that the gender context for female managers in the public service broadcaster, had shifted significantly: "I worked with men more senior to me who were very comfortable with powerful women in key positions Directors of Finance, 
Commercial, Programmes, and for me I was conscious of supporting female managers who were reporting to me ...."The extent to which these women could lead differently and yet be valued by the organisation is down to the willingness of women like Duignan to be the first in the positions, that is to act as leaders for organisational change and to conduct their leadership in a style that corresponds with a relational emphasis.

In 2013 Grady achieved the top role of Editor at the Irish Independent. On what it took to achieve the post Grady comments, "At a certain point if you're good at your job it's hard to ignore you." Grady names the exceptional skills required to get past being "ignored": "The women who were promoted were quite exceptional in their determination, dedication and ability, whereas mediocre men or slightly above average men could get into those positions ...." While Grady's appointment was publicly celebrated as a "first" for the newspaper in question, Grady was aware of the shifting sands of power within the organisation as she assumed what should have been a top-level decision-making job. Doing gender and doing power seemed to collide in a complex way as the post she achieved was in fact superseded by the appointment of an Editor in Chief. Grady spoke clearly of the complications inherent in women doing leadership:

I do think that once a role becomes feminised it does get watered down and does get deval-

ued ... I was conscious women had been put into some key positions in the organisation but there was always a layer above that was male, the editor in chief, the head of content under the restructuring was male, political editor, business editor, were all male.

Not only had Grady a layer above of masculine leadership she didn't have the same resources as her predecessor: "I didn't have a team of editors that reported to me. I came to the position as all the restructuring was happening and that was difficult ... I was only in the editor job for a year."The sustainability of women in leadership is clearly an issue for Grady even when women change the norms of entry for women in media work, change the norms for their participation in leadership, even then finally the nature of the leadership roles they are assigned can become compromised in a subtle but highly gendered way. Nonetheless the key point here is that the women's capacity to lead in a relational manner, as outlined above, their entry into media work, and their resilience in staying on to become leaders were all acts of relational leadership that led to fundamental social change for women in media industries.

\section{Conclusion: feminine or feminist leadership}

Relational leadership is a useful model for understanding the women's leadership as collaborative and as constructed in a gendered manner. Moreover many of the women's relational acts can be understood as leadership because they caused organisational change towards more gender equality in media industries. Nonetheless their leadership did not lead to a fundamental de-masculinisation of media work. While the women mostly identified as feminist, their relational leadership did not demand the systemic changes that feminist leadership seeks. The women's feminism was articulated in a number of ways, for instance in terms of the production work they did and their consciousness of the debt they owed to feminist activists of the 1970s. Duignan was particularly active as a producer of feminist media content in the 1980s when she was series producer, on a women's issues radio programme called "Women Today." Moreover her career progress, she acknowledges, was in the context of a very active feminist movement in 1970s Ireland that saw radio respond with campaigning 
feminist journalism. Similarly Shaw explicitly credits the relative ease of her entry into journalism to the work of a previous generation of female journalists, such as Kennedy and other journalists who were heavily active in the 1970s feminist movement in Ireland. Grady similarly explicitly identified as a feminist and, while her leadership fits well within the paradigm of feminine and relational, she was explicit about the limitations of incorporating any kind of feminist agenda into her work as editor:

There wasn't space in the time I was there to do anything about a feminist agenda ... In the space of a year it would have been hard to do anything about the tone of the place ... There was no block on doing a series on (feminism or) anything, there were no clashes or anything like that but there was so much change your focus is on managing resources to get a good paper out. Nobody was holding me back from a feminist agenda but my time as editor coincided with a period of enormous change.

While the women interviewed broadly identified as feminists, their leadership was limited in being proactively feminist in the sense that they did not actively seek to generate systemic changes within the media as an institution. The changes that occurred were shifts in social norms that incorporated women into a system of production that remained nonetheless masculinist. As Fletcher proposes:

If the new (feminine) leadership model is understood as simply a new approach that requires integrating relational skills ... it is likely to be incorporated into the dominant discourse ... without awareness of the deepest changes to structures, systems and work practices that would be needed

for feminist forms of leadership to emerge $(2004,657)$. For a feminist form of leadership to emerge leaders would need to be concerned with social transformation towards the absence of gendered roles and with gender justice as the ultimate aim of their leadership.

While the women interviewed gave a subjective account of their leadership as relational and as socially constructed in a gendered manner, and while the women's work towards greater gender equality in the norms of media work needs to be acknowledged as acts of leadership, their practice of leadership stopped short of constituting a feminist leadership within media industries. Feminine leadership does not explicitly seek to transform the organisational or institutional status quo regarding gender inequality in media industries. So while feminine leadership is increasingly incorporated at an organisational level, until women in senior decision-making roles can lead explicitly feminist forms of social change, requiring new mental models of how organisations and work can be led, then the ongoing issues of women's unequal participation in media industries and in its leadership will continue. How this form of leadership might emerge is a potentially rich vein of further study. In addition this small-scale Irish study could be built upon through comparison with other nation state cases, by examining feminine leadership across additional media platforms such as games industries and social media, and by further exploring the blocks on feminist leadership that exist in media industries and how the sector might in future be de-masculinised in order to facilitate a more overtly feminist form of leadership and gender equality in media industries.

\section{Acknowledgements}

I am very grateful to two anonymous reviewers and to Cindy Carter for generous comments on earlier drafts of this article. 


\section{Disclosure statement}

No potential conflict of interest was reported by the author.

\section{Notes on contributor}

Anne O'Brien is a lecturer with the Department of Media Studies at Maynooth University. She has published a number of articles on the representation of women in radio and television, on women workers in creative industries, and examined why women leave careers in screen production. She has published a monograph on state development and cultural industries. She is a member of Screen Producers Ireland and an appointee to the Broadcasting Authority of Ireland. E-mail: anne.obrien@nuim.ie

\section{References}

Antrobus, Peggy. 2000. "Transformational Leadership: Advancing the Agenda for Gender Justice." Gender and Development 8 (3): 50-56.

Barton, Tracy. 2006. "Feminist Leadership: Building Nurturing Academic Communities." Advancing Women's Leadership 21. www.advancingwomen.com/awl/fall2006/barton.htm

Bradford, David, and Allan Cohen. 1998. Power up. New York: Wiley.

Bryant, Gay. 1985. The Working Woman Report. New York: Simon and Schuster.

Butler, Judith. 1993. Bodies That Matter: On the Discursive Limits of "Sex". New York: Routledge.

Byerly, Carolyn M. 2011. Global Report on the Status of Women. Washington, DC: International Women's Media Foundation.

Byerly, Carolyn, and Karen Ross. 2004. Women and Media: A Critical Introduction. Oxford: Blackwell Publishing.

Eagly, Alice H. 2007. "Female Leadership Advantage and Disadvantage: Resolving the Contradiction." Psychology of Women Quarterly 31 (1): 1-12.

Eagly, Alice H., and Linda L. Carli. 2007. "Women and the Labyrinth of Leadership." Harvard Business Review 85 (9): 62-71.

European Institute for Gender Equality. 2013. Advancing Gender Equality in Decision-making in Media Organizations Report. Luxembourg: Publications Office of the European Union.

Fletcher, Joyce K. 2004. "The Paradox of Postheroic Leadership: An Essay on Gender, Power, and Transformational Change." The Leadership Quarterly 15: 647-661.

Fondas, Nanette. 1997. "Feminization Unveiled: Management Qualities in Contemporary Writing." Academy of Management Review 22 (1): 257-282.

Hegarty, Noirín. 2016. "The Family of Things." Podcast 9, Dublin: Athena Media http://podcastingireland. ie/? $\mathrm{p}=1490$

Hosking, Diane M., Dachler H. Peter, and Kenneth J. Gergen, eds. 1995. Management and Organization: Relational Alternatives to Individualism. Brookfield, CT: Avebury.

Lipman Blumen, Jean. 1996. The Connective Edge. San Francisco, CA: Jossey-Bass.

Melin-Higgins, Margareta. 2004. “Coping with Journalism: Gendered Newsroom Culture." In Gender and Newsroom Cultures, edited by Marjan de Bruin and Karen Ross, 197-222. Cresskill, NJ: Hampton Press.

Murrell, Kenneth.L. 1997. “Emergent Theories of Leadership for the Next Century: Towards Relational Concepts." Organization Development Journal 15 (3): 35-42.

O’Brien, Anne. 2014. "Men Own Television': Why Women Leave Media Work." Media, Culture \& Society 36 (8): 1207-1218.

O’ Brien, Anne. 2015. "Producing Television and Reproducing Gender." Television \& New Media. 16 (3): 259-274.

Ross, Karen. 2014. "Women in Decision Making Structures in Media." In Media and Gender: A Scholarly Agenda for the Global Alliance on Media and Gender, edited by A. V. Montiel, 37-40. France: UNESCO.

Ryan, Michelle K. and Haslam, S. Alexander. 2007. "The Glass Cliff: Exploring the Dynamics Surrounding Women's Appointment to Precarious Leadership Positions." Academy of Management Review 32: 549-572. 
Stead, Valerie, and Carole Elliott. 2009. Women's Leadership. Basingstoke: Palgrave Macmillan.

Steiner, Linda. 2015. “Glassy Architectures in Journalism." In Routledge Companion to Media and Gender, edited by Cynthia Carter, Linda Steiner and Lisa McLaughlin, 620-631. London: Routledge.

Uhl-Bien, Mary. 2011."Relational Leadership and Gender: From Hierarchy to Relationality and Relational Leadership Theory: Exploring the Social Processes of Leadership and Organizing." In Leadership Gender and Organization, edited by Patricia Werhane and Mollie Painter-Morland, 65-108. Dordrecht: Springer.

van Zoonen, Liesbet. 1989. "Professional Socialization of Feminist Journalists in the Netherlands." Women's Studies in Communication 12 (2): 1-21. 